\title{
Implications of Transitional Care Interventions on Hospital Readmissions in Patients with Destination Therapy Left Ventricular Assist Devices
}

\author{
Jackeline I. Iseler, DNP, RN, ACNS-BC \\ Michigan State University \\ Kelly L. Wierenga PhD, RN \\ Case Western Reserve University \\ Elizabeth C. Shaid MSN, CRNP and Karen Hirschman PhD, MSW \\ University of Pennsylvania
}

\section{Corresponding Author:}

Jackeline Iseler, DNP, RN, ACNS-BC

Michigan State University College of Nursing

1355 Bogue Street

East Lansing, Michigan State University

(517) 432-4907 Office

(517) 353-9953 Fax

jackeline.iseler@hc.msu.edu

Author Roles Statement: Jackeline Iseler DNP, RN, ACNS-BC devised the design and implementation, and analysis of the work. Jackeline Iseler, DNP, RN, ACNS-BC and Kelly Wierenga PhD, RN drafted the article. Kelly Wierenga PhD, RN, Elizabeth Shaid, MSN, CRNP, and Karen Hirschman $\mathrm{PhD}$, MSW provided critical revision of the article.

Acknowledgements: The authors would like to acknowledge Michigan State University College of Nursing and Jennifer Lareau-Gee for the preparation of this manuscript.

Conflict of Interest: No conflict of interest

Funding or Sources of Support: None to report

This is the author's manuscript of the article published in final edited form as: 


\section{Implications of Transitional Care Interventions on Hospital Readmissions in Patients with Destination Therapy Left Ventricular Assist Devices}

Heart failure (HF) affects 26 million patients globally (Ambrosy, Fonarow, Butler, \& Chioncel, 2014). Deterioration of the heart ventricles continues to be experienced by patients with advanced heart failure despite guideline-directed medical therapy (Marcuccilli, Casida, Bakas, \& Pagani, 2014; Yancy et al., 2013). For patients at high risk for mortality within a year, a left ventricular assist device (LVAD) should be considered (Feldman et al., 2013). An LVAD may be implanted in patients who are eligible for a heart transplant, known as bridge to transplant (BTT) (Gal \& Jaarsma, 2012; McMurray et al., 2012; Peura et al., 2012). Alternatively, some patients receive an LVAD as a long-term solution, or destination therapy (DT), if they are ineligible for transplant (Gal \& Jaarsma, 2012; Kirklin, Naftel, Kormos, \& Stevenson, 2013; McMurray et al., 2012; Shreenivas, Rame, \& Jessup, 2010). Patients with advanced age, high body mass index (BMI), high peripheral vascular resistance, recent malignancy, human immunodeficiency virus, or renal insufficiency are generally ineligible for a heart transplant and prompt consideration for DT LVAD (Miller \& Guglin, 2013).

The purposes of BTT and DT LVAD placements are distinct, with BTT allowing patients to wait for a transplant from the limited available organ donors (Pagani et al., 2009). Destination therapy is reserved for patients who do not meet the criteria for transplants and need mechanical circulatory support from an LVAD to improve their quality of life (QOL) and functional capacity (Miller \& Guglin, 2013; Slaughter et al., 2009). It is important to consider the needs of an LVAD 
patient following implantation as they transition from the inpatient to home environment, particularly for those DT patients expected to care for their LVAD long-term.

\section{Transitions of Care}

A transition of care is defined as a transfer of patient care from one type of setting to another while providing time-limited services targeted to prevent poor outcomes (Naylor, Aiken, Kurtzman, Olds, \& Hirschman, 2011) through coordination and continuity of care (Coleman, Parry, Chalmers, \& Min, 2006). Transitional care involves education of the patient and family, and coordination among the healthcare team based on a comprehensive, patient-centered plan of care by trained healthcare practitioners (Coleman et al., 2006). An optimal transition from hospital to home requires a multidisciplinary team approach and includes lifestyle modification by both patient and informal caregivers (Gal \& Jaarsma, 2012; Marcuccilli et al., 2014; Mountis \& Starling, 2009).

Informal caregivers are individuals with a significant relationship to the patient, such as a relative, partner, or friend, who provide care to the patient (Family Caregiver Alliance, 2017). As part of the home environment, informal caregivers are pivotal to the successful transition for patients with an LVAD. These caregivers are responsible for percutaneous exit-site care, anticoagulation management, monitoring of HF exacerbation symptoms, monitoring for signs of infection, healthy diet adherence, and recognizing signs and symptoms to report to the healthcare team as a requirement for transition from hospital to home (Bellumkonda \& Jacoby, 2013; Gal \& Jaarsma, 2012; Mountis \& Starling, 2009). All of these responsibilities can leave the caregiver feeling overwhelmed (Cicolini, Cerratti, Pelle, \& Simonetti, 2016).

\section{LVAD Patient Outcomes}


Hospital readmission rates for patients with an LVAD currently range from $26 \%$ to $76 \%$ (Hasin et al., 2013; Pagani et al., 2009; Iseler, Fox, \& Wierenga, 2018; Tsiouris, Paone, Nemeh, Brewer, \& Morgan, 2014; Williams et al., 2012). Leading causes of readmission in patients with an LVAD are bleeding, cardiac-related causes, infection, and thrombosis (Hasin et al., 2013). Recurrent HF accounts for one reason for readmissions (Hasin et al., 2013; Tsiouris et al., 2014). It is critical that patients and informal caregivers adhere to the medication regime, device maintenance, driveline care, and follow-up care with their healthcare team (Gandhi, McCue, \& Cole, 2016). Patient and caregiver communication with the healthcare team are pivotal and a thorough understanding of the transitions may be of utmost importance for LVAD patients. Interventions focused on these transitions from hospital to home have shown to decrease readmissions in patients with HF (Feltner et al., 2014; Naylor, Brooten, Campbell, Maislin, et al., 2004) and patients with an LVAD may demonstrate similar results.

Globally, over 15,000 people are living with a ventricular assist device (VAD) (Kirklin et al., 2015). Destination therapy LVAD recipients are now considered a new chronic patient population (Gal \& Jaarsma, 2012). From 2006 to 2012, there were over 6,600 LVAD implantations in the United States and Canada, and over $40 \%$ of these patients classified as DT in 2012 (Kirklin et al., 2013). The increasing number of LVAD implantations, and years of survival, challenge the provision of optimal care to meet implantation goals for patients and families (Gal \& Jaarsma, 2012), which include increasing patient survival, functional status, and QOL (Miller et al., 2007; Pagani et al., 2009; Shreenivas et al., 2010; Slaughter et al., 2009).

\footnotetext{
Aim

Specialized healthcare teams provide long-term care in collaboration with the high-level of care by the patient and their family to support the patients' outcomes (Gal \& Jaarsma, 2012).
} 
Evidence to guide healthcare teams in supporting the transitions for these patients and their families are lacking. The aims of this review were to explore components of transitional care interventions in patients with HF, identify components that may improve patient outcomes, and determine potential components appropriate for application in patients with DT LVAD.

\section{Methods}

\section{Design}

An integrative review was completed, which allowed for the inclusion of a broad range of sources with varied methodologies. The review structure was guided by Whittemore and Knafl's (2005) methodology, including the following stages: problem identification, literature search, data evaluation, data analysis, and presentation. Depending on the type of study, the methodological quality was assessed using the Rapid Critical Appraisal Questions for Randomized Controlled Trials method (O'Mathuna, Fineout-Overholt, \& Johnson, 2011) or the Overview Questions for Critical Appraisal of Quantitative Studies (O'Mathuna et al., 2011).

\section{Problem Identification}

Based on the background literature, it is clear that transitional care interventions may be effective in improving health outcomes for patients with HF (Naylor, Brooten, Campbell, Maislin et al., 2004). Unfortunately, no immediate literature was discovered that identified what makes transitional care interventions more or less effective, or if they were appropriate for use in a highly specific DT LVAD population. As such, variables of interest and a sampling frame were identified to respond to the study aim (Whittemore \& Knafl, 2005). The variables of interest included transitional care, patients with HF or ventricular assist devices, and readmission to the hospital. The sampling frame included all types of empirical studies such as quantitative, qualitative, and other reviews. 


\section{Literature Search}

The three electronic databases searched for this review were The Cumulative Index to Nursing and Allied Health Literature (CINAHL), PubMed, and ProQuest. The following CINAHL headings, medical subject headings, and keywords were used to search for relevant articles: "heart failure," "heart-assist device," "ventricular assist device," "continuity of patient care," "transitional care," "patient readmission," "rehospitaliz*," "readmit*," and "readmission". The search limitations were set to peer reviewed, English language, and age $\geq 18$ years. The initial search did not limit the literature to a specific period. Reference lists within identified articles were examined as an additional method of obtaining relevant literature.

\section{Article Selection}

The Preferred Reporting Items for Systematic Reviews and Meta-Analyses (PRISMA) guidelines aided the selection of articles (Liberati et al., 2009). Two reviewers examined articles for inclusion criteria. Included articles contained adult study participants. Additionally, studies needed to include one or more of the following components: home visits, assistance with community resources, coaching, self-management support, transitions coach, case management, an individualized discharge plan implemented by healthcare staff, telephone calls, and/or intense follow-up. Distinct components such as those above were critical to identifying articles with increased effectiveness.

\section{Analysis and Evaluation of the Literature}

Extracted information was based on patient diagnosis, intervention type and length, and outcomes. Randomized controlled trials were reviewed for methodological quality using the Rapid Critical Appraisal Questions for Randomized Controlled Trials method (O'Mathuna et al., 
2011). The quality of non-randomized controlled trial articles were reviewed using the Overview Questions for Critical Appraisal of Quantitative Studies (O'Mathuna et al., 2011).

\section{Results}

\section{Search Outcomes}

The initial CINAHL, PubMed, and ProQuest searches resulted in 93, 171, and 40 articles, respectively $(N=304)$, and were reviewed independently by two reviewers (See Fig. 1). If any disagreement or discrepancies occurred between the reviews, they were resolved through discussion and consensus agreement. A total of 291 articles were removed for not meeting the inclusion criteria. Duplicate articles were identified and removed $(n=6)$. A search of references from each included article identified six additional articles not captured in the CINAHL, PubMed, or ProQuest searches (Lefebvre, Manheimer, \& Glanville, 2008). A final sample of 13 articles was included in this literature review. The PRISMA (Liberati et al., 2009) statement was used to outline the search strategy.

\section{Data Evaluation}

To evaluate the data, an examination of the methodological quality was conducted. The final sample of articles included eight randomized controlled trials (RCTs) (Coleman, Parry, Chalmers, \& Min, 2006; Harrison et al., 2002; Linden \& Butterworth, 2014; Naylor, Brooten, Jones, et al., 1994; Naylor, Brooten, Campbell, Jacobsen et al., 1999; Naylor, Brooten, Campbell, Maislin, et al., 2004; Rich et al., 1995; Yu et al., 2015), three quasi-experimental studies (Neff, Madigan, \& Narsavage, 2003; Ohuabunwa, Jordan, Shah, Fost, \& Flacker, 2013; Williams, Akroyd, \& Burke, 2010), one observational study (Russell, Rosati, Sobolewski, Marren, \& Rosenfeld, 2011), and one prospective pilot study (Stauffer et al., 2011).

\section{Included Study Results}


The interventions in the selected studies were registered nurse (RN) led. All but one study was conducted in the United States, with the other conducted in China. All studies described the interventions used, some also analyzed the cost of the program. The patient outcomes described in the studies were measured as rehospitalization rates, length of stay, outpatient resource utilization, and QOL. All articles reviewed are presented in Table 1.

\section{Study Characteristics and Quality Assessment}

For the eight randomized controlled trials, methodological quality was assessed using the Rapid Critical Appraisal Questions for Randomized Controlled Trials method (O'Mathuna et al., 2011). This strategy examines randomization, study results, and clinical relevance. All eight RCT used randomization of subjects in assigning them to the intervention or control groups (Coleman et al., 2006; Harrison et al., 2002; Linden \& Butterworth, 2014; Naylor, Brooten, Jones et al., 1994; Naylor, Brooten, Campbell, Jacobsen et al., 1999; Naylor, Brooten, Campbell, Maislin et al., 2004; Rich et al., 1995; Yu et al., 2015). Five of the studies (Harrison et al., 2002; Linden \& Butterworth, 2014; Naylor, Brooten, Campbell, Jacobsen et al., 1999; Naylor, Brooten, Campbell, Maislin, et al., 2004; Rich et al., 1995) and revealed the treatment allocation to the research assistants, members of the study team, and the patients after randomization. In the other studies, Coleman et al. (2006) reported that the research assistants were blinded to the participants' allocation statuses, while Naylor, Brooten, Jones et al. (1994) and Yu et al. (2015) did not mention when the treatment allocation was revealed.

For the studies that were not RCTs, methodological quality was reviewed with the Overview Questions for Critical Appraisal of Quantitative Studies. This method examined the purpose of the study, sample size, and validity and reliability of the measurements; analyzed the data; determined unforeseeable events during the study; compared the results to the research; and 
determined how the research may affect clinical practice (O'Mathuna et al., 2011). Russell et al. (2011) conducted a retrospective observational study in which they compared patients prior to the implementation of the intervention (in 2009) to the intervention group in the transitional program (in 2010), in order to prevent or reduce contamination bias. In a prospective pilot study conducted by Stauffer et al. (2011), the authors implemented a pilot program and compared participants' data to patients who had opted out of the program, and found no significant differences between the two groups. For two quasi-experimental studies (Ohuabunwa et al., 2013; Williams, Akroyd et al., 2010), transitional care groups were compared to historical patient data. In addition to comparing to historical data, Obuabunwa et al. (2013) also conducted a pretest/posttest evaluation in their single intervention group. Finally, Neff, Madigan, and Narsavage (2003) conducted a prospective, nonrandomized trial and assigned the participants according to their county of residence.

\section{Data Analysis}

As much of the empirical evidence included in this review does not contain primary data with measurement consistency between articles, analysis of data in this review is limited to ordering and categorizing data. Summarization is based on extracted data compared in the categories of participants and settings, types of interventions, and a variety of patient and cost outcomes.

Types of intervention used in intervention groups. Registered nurses or advanced practice registered nurses (APRNs) led the interventions in all of the included studies. The intensity level of post-discharge contact with patients was determined by type and frequency of post-discharge contact (see Table 2). Improved communication and follow-up were common elements of the discharge components of the interventions. Follow-up appointments, home visits, 
and calls were other common discharge components included in study interventions. Nine studies provided phone numbers to patients to enable them to contact staff if they had questions or concerns (Harrison et al., 2002; Linden \& Butterworth, 2014; Naylor, Brooten, Campbell, Jacobsen, et al., 1999; Naylor, Brooten, Campbell, Maislin, et al., 2004; Neff, Madigan, \& Narsavage, 2003; Ohuabunwa et al., 2013; Rich et al., 1995; Russell et al., 2011; Stauffer et al., 2011).

Patient education was also a typical component of the interventions and was implemented using various methods. Eight studies provided disease-specific education (Naylor, Brooten, Jones et al., 1994; Naylor, Brooten, Campbell, Jacobsen et al., 1999; Naylor, Brooten, Campbell, Maislin et al., 2004; Neff et al., 2003; Rich et al., 1995; Stauffer et al., 2011; Williams, Akroyd et al., 2010; Yu et al., 2015), while other studies delivered self-management support through a patient workbook (Harrison et al., 2002), coaching (Russell et al., 2011), reinforcement of teaching (Naylor, Brooten, Campbell, Jacobsen et al., 1999), or information on medication selfmanagement (Coleman et al., 2006).

A commonality of the study interventions was being nursing-led, either by RNs or APRNs, with different intensity levels, determined by the type and frequency of the interventions. The studies also described improved communication between the patient, facilities, or other healthcare providers. In addition to the improved communication methods, discharge elements were described in the studies as follow-up appointments, home visits, and phone calls to the patients. All but two studies included home visits as part of the transitional care interventions (Linden \& Butterworth, 2014; Naylor, Brooten, Jones et al., 1994). Additionally, all studies identified patient education execution, in various methods, as an intervention. 


\section{Patient outcomes.}

Rehospitalizations. All-cause rehospitalization was measured in all 13 included studies. Significant decreases in rehospitalizations were shown in eight studies. These studies implemented an intervention that was at least at a moderate level of intensity (Coleman et al., 2006; Naylor, Brooten, Jones et al., 1994; Naylor, Brooten, Campbell, Jacobsen et al., 1999; Naylor, Brooten, Campbell, Maislin et al., 2004; Neff et al., 2003; Rich et al., 1995; Russell et al., 2011; Stauffer et al., 2011). Yu et al. (2015) reported a significant decrease in rehospitalizations within six weeks. Two studies that implemented a moderate level of intensity intervention did not report significant decreases in rehospitalizations; however, they were able to show a nonsignificant decrease within 30 days (Ohuabunwa et al., 2013; Williams, Akroyd et al., 2010). Only one of the low-intensity level studies had a decrease in rehospitalizations, and it was non-significant (Harrison et al., 2002).

Emergency room visits, acute care use, and primary care services. In addition to rehospitalization, five studies also examined acute care use, such as emergency room visits and primary care services (Harrison et al., 2002; Linden \& Butterworth, 2014; Naylor, 1999; Neff et al., 2003; Ohuabunwa et al., 2013). All-cause emergency room visits ranged in occurrence from 24 hours to 90 days after discharge (Harrison et al., 2002; Linden \& Butterworth, 2014; Neff et al., 2003) and up to 365 days (Ohuabunwa et al., 2013). Transitional care interventions were associated with an overall decrease in use of emergency department services (Harrison et al., 2002; Neff et al., 2003; Ohuabunwa et al., 2013). Significant reductions in emergency room visits were shown at 30 days (Neff et al., 2003) and after 12 weeks (Harrison et al., 2002).

Quality of life. Patient QOL was shown to have significantly improved in the three studies examining this outcome (Harrison et al., 2002; Naylor, Brooten, Jones et al., 1994; Rich 
et al., 1995). Overall QOL improvements were significant in two studies at 12 weeks (Harrison et al., 2002; Rich et al., 1995). Although improvements to components of patient QOL were shown within each of these studies, inconsistency in the measurement and results was apparent.

Cost outcome. Variability existed in the methods used to calculate cost in the studies. Six studies included an analysis of cost and were able to show cost savings with the use of transitional care interventions (Coleman et al., 2006; Naylor, Brooten, Jones et al., 1994; Naylor, Brooten, Campbell, Jacobsen et al., 1999; Naylor, Brooten, Campbell, Maislin et al., 2004, Rich et al., 1995; Stauffer et al., 2011). The calculated cost savings in one study used the annual cost of the care transition intervention and itemized annual costs for the program, and was able to show significant reduction in cost at 90 and 180 days (Coleman et al., 2006). Naylor, Brooten, Jones et al. (1994) were able to show a significant decrease in total charges between two and six weeks after discharge, and similar results at six weeks after discharge. Costs per patient was also found to be significantly less in the intervention group at 24 weeks after discharge (Naylor, Brooten, Campbell, Jacobsen et al., 1999), and the mean at 52 weeks (Naylor, Brooten, Campbell, Maislin et al., 2004). Rich et al. (1995) found the cost of care per patient to be less in the transitional care intervention group, and readmission costs to be less as well $(p=0.03)$. Stauffer et al. (2011) was able to show total direct costs for patients in the transitional care intervention groups; however, from the hospital perspective, the intervention lost revenue in preventing readmissions.

\section{Discussion}

The aim of the review was to explore the existing transitions of care interventions for patients and its potential for application in patients with DT LVAD. While it is clear transition care reduces cost and improves outcomes, this review can begin to explain which aspects of 
transitional care may be effective in this specific patient population and how the effectiveness of the intervention can be evaluated. This review can also be used as a foundation for the expansion of transitional care interventions in the LVAD patient population to reduce rehospitalization rates. Based on careful examination of the literature, the authors' determined there were no studies investigating transitional care in the LVAD patient population, HF was included in patients' medical diagnoses in 12 of the 13 studies, and chronic obstructive pulmonary disease was the main diagnosis in the remaining study (Neff et al., 2003).

The interventions in the studies applied various methods to improve communication between patients and the facilities or the patient's primary care providers. The type and frequency of post-discharge contact was categorized into levels of intensity and were nursingled. In addition, the studies identified discharge elements, such as follow-up appointments, home visits, and phone calls to the patients, as improved methods of communication. All studies discussed patient education as an intervention applied through varying approaches. Additionally, all but two studies included home visits as part of the transitional care interventions (Linden \& Butterworth, 2014; Naylor, Brooten, Jones, et al., 1994).

Naylor et al. (1994) researchers were able to show a decrease in readmissions of patients in the medical diagnosis-related group (DRG) in comparison to the surgical DRG patients. However, LVAD patients would still be considered HF patients despite having undergone surgery for the LVAD implantation. It is plausible that similar results could be achieved within the LVAD patient population through the implementation of a comprehensive transitional care plan. Because LVAD patients still need to work on HF self-management skills, implementation of transitional care interventions in the LVAD patient population should include newly implanted device patients and rehospitalized LVAD patients. 


\section{Conclusion}

Transitional care interventions have been studied in HF patients and have shown a decrease in hospital readmissions and hospital costs and an improved QOL when compared to usual care. It is important to note, however, that the intensity of which an intervention is applied is critical in changing these outcomes. The more intensely the intervention is applied, the better the results. Considering the wide range of 30-day rehospitalization rates for patients with an LVAD, hospitals caring for these patients need to assess how their programs can best help lower these rehospitalization rates. While additional research is needed, LVAD hospitals should consider implementing transitional care interventions of at least moderate intensity to reduce their rate of LVAD patient rehospitalization.

\section{Implications for Practice}

Nurses are well positioned to provide to and lead several of the transitional care interventions, such as conducting home visits, follow-up phone calls, and individualizing patient education. Nurses should also work with the patient, family, and healthcare team in developing an evidence-based comprehensive and individualized plan of care to improve coordination of care and target the healthcare needs and goals of the patient (Naylor, Feldman et al., 2009). Nurses should lead communication between patients, facilities, and the patient's primary care providers at the time of and after patient's transition. Moreover, the transitional care interventions would need to be at least at a moderate level of intensity to have maximum potential impact on patient outcomes. Research on transitional care interventions in patients with an LVAD may be able to identify which interventions and in what combinations are effective. 


\section{References}

Ambrosy, A. P., Fonarow, G. C., Butler, J., \& Chioncel, O. (2014). The global health and economic burden of hospitalizations for heart failure: Lessons learned from hospitalized heart failure registries. Journal of the American College of Cardiology, 63(12), 11231133. doi:10.1016/j.jacc.2013.11.053

Bellumkonda, L., \& Jacoby, D. (2013). Hospital to home with mechanical circulatory support. Current Heart Failure Reports, 10(3), 212-218. doi:10.1007/s11897-013-0143-y

Cicolini, G., Cerratti, F., Pelle, C. D., \& Simonetti, V. (2016). The experience of family caregivers of patients with a left ventricular assist device: An integrative review. Progress in Transplantation, 26(2), 135-148. doi:10.1177/1526924816640648

Coleman, E. A., Parry, C., Chalmers, S., \& Min, S. (2006). The care transitions intervention: Results of a randomized controlled trial. Archives of Internal Medicine, 166(17), 18221828. doi:10.1001/archinte.166.17.1822

Family Caregiver Alliance. (2017). Definitions. Retrieved from www.caregiver.org Feldman, D., Pamboukian, S. V., Teuteberg, J. J., Birks, E., Lietz, K., Moore, S. A., . . Lung, T. (2013). The 2013 International Society for Heart and Lung Transplantation Guidelines for mechanical circulatory support: Executive summary. Journal of Heart and Lung Transplantation, 32(2), 157-187. doi:10.1016/j.healun.2012.09.013

Feltner, C., Jones, C. D., Cené, C. W., Zheng, Z.-J., Sueta, C. A., Coker-Schwimmer, E. J. L., . . . Jonas, D. E. (2014). Transitional care interventions to prevent readmissions for persons with heart failure: A systematic review and meta-analysis. Annals of Internal Medicine, 160(11), 774-784. doi:10.7326/M14-0083 
Gal, B. T., \& Jaarsma, T. (2012). Patients with a left ventricular assist device: The new chronic patient in cardiology. European Journal of Cardiovascular Nursing, 11(4), 378-379. doi:10.1177/1474515112441145

Gandhi, J., McCue, A., \& Cole, R. (2016). Nonadherence in the advanced heart failure population. Current Heart Failure Reports, 13(2), 77-85. doi:10.1007/s11897-016-02877

Harrison, M. B., Browne, G. B., Roberts, J., Tugwell, P., Gafni, A., \& Graham, I. D. (2002). Quality of life of individuals with heart failure: A randomized trial of the effectiveness of two models of hospital-to-home transition. Medical Care, 40(4), 271-282.

Hasin, T., Marmor, Y., Kremers, W., Topilsky, Y., Severson, C. J., Schirger, J. A., . . Kushwaha, S. S. (2013). Readmissions after implantation of axial flow left ventricular assist device. Journal of the American College of Cardiology, 61(2), 153-163. doi:10.1016/j.jacc.2012.09.041

Iseler, J., Fox, J., \& Wierenga, K. (2018). Performance improvement to decrease readmission rates for patients with a left ventricular assist device. Progress in Transplantation, Advance online publication. doi:10.1177/1526924818765820

Kirklin, J. K., Naftel, D. C., Kormos, R. L., \& Stevenson, L. W. (2013). Fifth INTERMACS annual report: Risk factor analysis from more than 6,000 mechanical circulatory support patients. The Journal of Heart and Lung Transplantation, 32(2), 141-156. doi:10.1016/j.healun.2012.12.004

Lefebvre, C., Manheimer, E., \& Glanville, J. (2008). Searching for studies. In J. P. T. Higgins and S. Green (Eds.), Cochrane Handbook for Systematic Reviews of Interventions (pp. 95-150). Chichester: Wiley-Blackwell John. 
Liberati, A., Altman, D. G., Tetzlaff, J., Mulrow, C., Gøtzsche, P. C., Ioannidis, J. P. A., . . . Moher, D. (2009). The PRISMA statement for reporting systematic reviews and metaanalyses of studies that evaluate health care interventions: Explanation and elaboration. PLoS Medicine, 6(7), e1000100. doi:10.1371/journal.pmed.1000100

Linden, A., \& Butterworth, S. W. (2014). A comprehensive hospital-based intervention to reduce readmissions for chronically ill patients: A randomized controlled trial. American Journal of Managed Care, 20(10), 783-792.

Marcuccilli, L., Casida, J., Bakas, T., \& Pagani, F. D. (2014). Family caregivers' inside perspectives: Caring for an adult with a left ventricular assist device as a destination therapy. Progress in Transplantation, 24(4), 332-340.

McMurray, J. J., Adamopoulos, S., Anker, S. D., Auricchio, A., Bohm, M., Dickstein, K., .. . Ponikowski, P. (2012). ESC guidelines for the diagnosis and treatment of acute and chronic heart failure 2012: The Task Force for the Diagnosis and Treatment of Acute and Chronic Heart Failure 2012 of the European Society of Cardiology. Developed in collaboration with the Heart Failure Association (HFA) of the ESC. European Journal of Heart Failure, 14(8), 803-869. doi:10.1093/eurjhf/hfs105

Miller, L. W., \& Guglin, M. (2013). Patient selection for ventricular assist devices: A moving target. Journal of the American College of Cardiology, 61(12), 1209-1221.

Miller, L. W., Pagani, F. D., Russell, S. D., John, R., Boyle, A. J., Aaronson, K. D., .. . Frazier, O. H. (2007). Use of a continuous-flow device in patients awaiting heart transplantation. The New England Journal of Medicine, 357(9), 885-896. doi:http://dx.doi.org/10.1056/NEJMoa067758 
Mountis, M. M., \& Starling, R. C. (2009). Management of left ventricular assist devices after surgery: Bridge, destination, and recovery. Current Opinion in Cardiology, 24(3), 252256. doi:10.1097/HCO.0b013e32832c7c09

Naylor, M., Brooten, D., Jones, R., Lavizzo-Mourey, R., Mezey, M., \& Pauly, M. (1994). Comprehensive discharge planning for the hospitalized elderly: A randomized clinical trial. Annals of Internal Medicine, 120(12), 999-1006.

Naylor, M. D., Aiken, L. H., Kurtzman, E. T., Olds, D. M., \& Hirschman, K. B. (2011). The importance of transitional care in achieving health reform. Health Affairs, 30(4), 746754. doi:10.1377/hlthaff.2011.0041

Naylor, M. D., Brooten, D., Campbell, R. L., Jacobsen, B. S., Mezey, M. D., Pauly, M. V., \& Schwartz, J. S. (1999). Comprehensive discharge planning and home follow-up of hospitalized elders: A randomized clinical trial. Journal of the American Medical Association, 281(7), 613-620.

Naylor, M. D., Brooten, D. A., Campbell, R. L., Maislin, G., McCauley, K. M., \& Schwartz, J. S. (2004). Transitional care of older adults hospitalized with heart failure: A randomized, controlled trial. Journal of the American Geriatrics Society, 52(5), 675-684. doi:10.1111/j.1532-5415.2004.52202.x

Naylor, M. D., Feldman, P. H., Keating, S., Koren, M. J., Kurtzman, E. T., Maccoy, M. C., \& Krakauer, R. (2009). Translating research into practice: Transitional care for older adults. Journal of Evaluation in Clinical Practice, 15(6), 1164-1170. doi:10.1111/j.13652753.2009.01308.x 
Neff, D. F., Madigan, E., \& Narsavage, G. (2003). APN-directed transitional home care model: Achieving positive outcomes for patients with COPD. Home Healthcare Nurse, 21(8), $543-550$.

O'Mathuna, D. P., Fineout-Overholt, E., \& Johnson, L. (2011). Critically appraising quantitative evidence for clinical decision making. In B. M. Melnyk \& E. Fineout-Overholt (Eds.), Evidence-based practice in nursing and healthcare (2nd ed., pp. 81-134). Philadelphia, PA: Wolters Kluwer Lippincott Williams \& Wilkins.

Ohuabunwa, U., Jordan, Q., Shah, S., Fost, M., \& Flacker, J. (2013). Implementation of a care transitions model for low-income older adults: A high-risk, vulnerable population. Journal of the American Geriatrics Society, 61(6), 987-992. doi:10.1111/jgs.12276

Pagani, F. D., Miller, L. W., Russell, S. D., Aaronson, K. D., John, R., Boyle, A. J., . . . HeartMate, I. I. I. (2009). Extended mechanical circulatory support with a continuousflow rotary left ventricular assist device. Journal of the American College of Cardiology, 54(4), 312-321. doi:10.1016/j.jacc.2009.03.055

Peura, J. L., Colvin-Adams, M., Francis, G. S., Grady, K. L., Hoffman, T. M., Jessup, M., . . . Toole, J. M. (2012). Recommendations for the use of mechanical circulatory support: Device strategies and patient selection: A scientific statement from the American Heart Association. Circulation, 126(22), 2648-2667. doi:10.1161/CIR.0b013e3182769a54

Rich, M. W., Beckham, V., Wittenberg, C., Leven, C. L., Freedland, K. E., \& Carney, R. M. (1995). A multidisciplinary intervention to prevent the readmission of elderly patients with congestive heart failure. The New England Journal of Medicine, 333(18), 11901195. doi:10.1056/NEJM199511023331806 
Russell, D., Rosati, R. J., Sobolewski, S., Marren, J., \& Rosenfeld, P. (2011). Implementing a transitional care program for high-risk heart failure patients: Findings from a communitybased partnership between a certified home healthcare agency and regional hospital. Journal for Healthcare Quality, 33(6), 17-23; quiz 23-14. doi:10.1111/j.19451474.2011.00167.x

Shreenivas, S. S., Rame, J. E., \& Jessup, M. (2010). Mechanical circulatory support as a bridge to transplant or destination therapy. Current Heart Failure Reports, 7(4), 159-166. doi: 10.1007/s11897-010-0026-4

Slaughter, M. S., Rogers, J. G., Milano, C. A., Russell, S. D., Conte, J. V., Feldman, D., . . Frazier, O. H. (2009). Advanced heart failure treated with continuous-flow left ventricular assist device. The New England Journal of Medicine, 361(23), 2241-2251. doi:http://dx.doi.org/10.1056/NEJMoa0909938

Stauffer, B. D., Fullerton, C., Fleming, N., Ogola, G., Herrin, J., Stafford, P. M., \& Ballard, D. J. (2011). Effectiveness and cost of a transitional care program for heart failure: A prospective study with concurrent controls. Archives of Internal Medicine, 171(14), 1238-1243. doi:10.1001/archinternmed.2011.274

Tsiouris, A., Paone, G., Nemeh, H. W., Brewer, R. J., \& Morgan, J. A. (2014). Factors determining post-operative readmissions after left ventricular assist device implantation. The Journal of Heart and Lung Transplantation, 33(10), 1041-1047. doi:10.1016/j.healun.2014.05.009

Whittemore, R., \& Knafl, K. (2005). The integrative review: Updated methodology. Journal of Advanced Nursing, 52(5), 546-553. doi:10.1111/j.1365-2648.2005.03621.x 
Williams, C. T., Jennings, D., Karadolian, S., Chamaria, S., Tita, C., Nemeh, H., . . Brewer, R. (2012). Analysis of cost for readmissions after continuous flow left ventricular assist device implantation: A single center experience. Journal of the American College of Cardiology, 59(13s1), E1018-E1018.

Williams, G., Akroyd, K., \& Burke, L. (2010). Evaluation of the transitional care model in chronic heart failure. British Journal of Nursing, 19(22), 1402-1407.

Yancy, C. W., Jessup, M., Bozkurt, B., Butler, J., Casey, D. E., Drazner, M. H., . . Wilkoff, B. L. (2013). 2013 ACCF/AHA guideline for the management of heart failure: A report of the American College of Cardiology Foundation/American Heart Association Task Force on practice guidelines. Journal of the American College of Cardiology, 62(16), e147e239. doi:https://doi.org/10.1016/j.jacc.2013.05.019

Yu, D. S. F., Lee, D. T. F., Stewart, S., Thompson, D. R., Choi, K. C., \& Yu, C. M. (2015). Effect of nurse-implemented transitional care for Chinese individuals with chronic heart failure in Hong Kong: A randomized controlled trial. Journal of the American Geriatrics Society, 63(8), 1583-1593. doi:10.1111/jgs.13533 


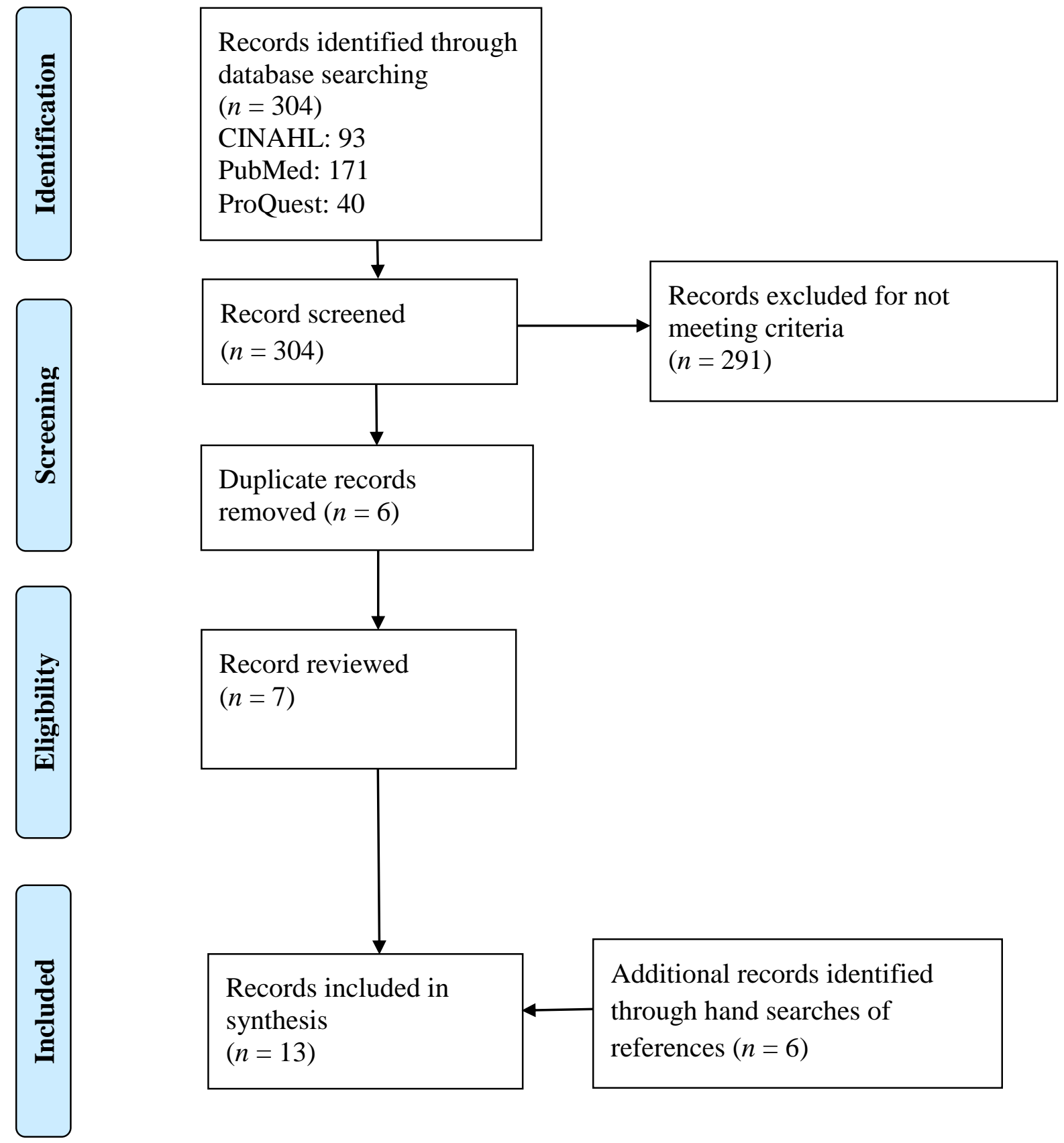

Figure 1: Flow diagram of evidence search and selection process 
Table 1 Summary of Articles Included in the Review

\begin{tabular}{llllll}
\hline Authors & Sample & Study Type & Outcomes & Intervention & Results \\
\hline $\begin{array}{l}\text { Coleman et } \\
\text { al, 2006 }\end{array}$ & & Rehospitalization rates & 28 days & Rehospitalization rates at 30 days \\
& & & APRN & Transition coach & $(p=0.048)$ \\
& & & & Mean hospital costs at 180 days \\
& & & &
\end{tabular}

\begin{tabular}{lllll}
\hline Harrison et & $N=192$ & Prospective, & Quality of life: & 12 weeks \\
al. 2002 & & RCT & Readmission rates & RN-led \\
& & ED use & Patient education \\
& & & Minimum of 2 visits
\end{tabular}

\begin{tabular}{llll}
\hline $\begin{array}{l}\text { Linden \& } \\
\text { Butterwort } \\
\text { h, 2014 }\end{array}$ & $N=512$ & $\begin{array}{l}\text { Parallel- } \\
\text { group, } \\
\text { stratified, } \\
\text { RCT }\end{array}$ & Readmission rates \\
\hline $\begin{array}{l}\text { Naylor et } \\
\text { al., 1994 }\end{array}$ & $N=276$ & RCT & $\begin{array}{l}\text { Rehospitalization rate } \\
\text { Charges }\end{array}$ \\
\hline
\end{tabular}

90 days $\quad$ No statistical difference

Intervention group:

- Better MLHFQ at 12 weeks

$$
(p<0.001) \text {. }
$$

ED first visit $(p=0.03)$

Hospital readmissions in 12 weeks: Control group 31\%, Intervention group 23\% No statistical difference between RN-led 30-day or 90-day readmission No home visits rates.

\begin{tabular}{|c|c|c|c|}
\hline $\begin{array}{l}\text { Naylor et } \\
\text { al., } 1994\end{array}$ & $N=276 \quad \mathrm{RCT}$ & $\begin{array}{l}\text { Rehospitalization rate } \\
\text { Charges }\end{array}$ & $\begin{array}{l}\text { Two weeks } \\
\text { Gerontologic nurse } \\
\text { specialist } \\
\text { Discharge visit } \\
\text { Telephone outreach } \\
\text { after discharge }\end{array}$ \\
\hline
\end{tabular}

\begin{tabular}{|c|c|c|c|c|c|}
\hline & & & & & $1,3 / 4(108 \pm 10)$ \\
\hline $\begin{array}{l}\text { Naylor et } \\
\text { al., } 1999\end{array}$ & $N=363$ & RCT & $\begin{array}{l}\text { Readmission rates } \\
\text { Acute care visits, costs } \\
\text { Functional status } \\
\text { Depression }\end{array}$ & $\begin{array}{l}\text { Four weeks in length } \\
\text { APRN led } \\
\text { At least two home } \\
\text { visits } \\
\text { Weekly APRN } \\
\text { initiated telephone } \\
\text { contact with patients } \\
\text { or caregivers }\end{array}$ & $\begin{array}{l}\text { Readmissions and hospital days } \\
(p<0.001) \\
\text { Acute care visits after discharge } \\
(p=0.77) \\
\text { Acute care visits after discharge } \\
\text { costs }(p=0.72) \\
\text { Functional status } p=0.33 \\
\text { Depression } p=20\end{array}$ \\
\hline $\begin{array}{l}\text { Naylor et } \\
\text { al., } 2004\end{array}$ & $N=239$ & $\mathrm{RCT}$ & $\begin{array}{l}\text { Rehospitalization rate } \\
\text { Costs } \\
\text { Quality of life }\end{array}$ & $\begin{array}{l}\text { Three months } \\
\text { APRN-directed } \\
\text { Discharge planning }\end{array}$ & $\begin{array}{l}\text { Rehospitalization or death }(p= \\
0.01) \\
\text { Mean costs }(p=0.002) \\
\text { Overall quality of life }(p<0.05)\end{array}$ \\
\hline $\begin{array}{l}\text { Neff et al., } \\
2003\end{array}$ & $N=80$ & $\begin{array}{l}\text { Prospective } \\
\text { quasi- } \\
\text { experimental } \\
\text { design }\end{array}$ & $\begin{array}{l}\text { OASIS Data: } \\
\text { Health service use }\end{array}$ & $\begin{array}{l}30 \text { days } \\
\text { APRN-directed } \\
\text { Home visits }\end{array}$ & $\begin{array}{l}\text { Depressive feelings: } p<0.05 \\
\text { Activity of daily living: } p<0.05 \\
\text { Length of stay }(p<0.05) \\
\text { Rehospitalizations } M(p<0.05) \\
\text { Acute care visits }(p<0.05)\end{array}$ \\
\hline $\begin{array}{l}\text { Ohuabunw- } \\
\text { a et al., } \\
2013\end{array}$ & $N=104$ & $\begin{array}{l}\text { Quasi- } \\
\text { experimental } \\
\text { design }\end{array}$ & $\begin{array}{l}\text { Readmission } \\
\text { ED visits } \\
\text { Primary care services }\end{array}$ & $\begin{array}{l}\text { Four weeks } \\
\text { RN-led (coach) } \\
\text { Home visits }\end{array}$ & $\begin{array}{l}\text { Readmission rates and ED were } \\
\text { not significantly lower } \\
\text { Outpatient primary care services: } \\
(30 \text { days }) p<0.001\end{array}$ \\
\hline $\begin{array}{l}\text { Rich et al., } \\
1995\end{array}$ & $N=282$ & $\begin{array}{l}\text { Prospective, } \\
\text { RCT }\end{array}$ & $\begin{array}{l}\text { Readmission rate } \\
\text { Quality of life } \\
\text { Costs }\end{array}$ & $\begin{array}{l}\mathrm{RN} \text {-directed } \\
90 \text { days } \\
\text { Intensive follow-up. }\end{array}$ & $\begin{array}{l}\text { 90-day readmission }(p=0.003) \\
\text { Quality of life }(p=0.0001) \\
\text { Readmission costs }(p=0.003)\end{array}$ \\
\hline $\begin{array}{l}\text { Russell et } \\
\text { al., } 2011\end{array}$ & $N=447$ & $\begin{array}{l}\text { Retrospective } \\
\text { observational }\end{array}$ & Rehospitalization rate. & $\begin{array}{l}\text { RN-led } \\
60 \text { days }\end{array}$ & $\begin{array}{l}\text { 30-day rehospitalization }(p< \\
0.01)\end{array}$ \\
\hline $\begin{array}{l}\text { Stauffer et } \\
\text { al., } 2011\end{array}$ & $N=140$ & $\begin{array}{l}\text { Prospective } \\
\text { pilot study }\end{array}$ & $\begin{array}{l}\text { Readmission rate } \\
\text { Cost }\end{array}$ & $\begin{array}{l}\text { APRN-led } \\
\text { Three months } \\
\text { Home visits } \\
\end{array}$ & $\begin{array}{l}\text { Readmission rates reduced } \\
\text { Costs: not significant }\end{array}$ \\
\hline $\begin{array}{l}\text { Williams, } \\
\text { Akroyd, \& } \\
\text { Burke, } \\
2010\end{array}$ & $N=97$ & $\begin{array}{l}\text { Quasi- } \\
\text { experimental } \\
\text { design }\end{array}$ & Readmission rate & $\begin{array}{l}\text { APRN-led } \\
\text { Follow-up } \\
\text { arrangements }\end{array}$ & $\begin{array}{l}\text { 30-day readmission rate }(p= \\
0.526) \\
\text { Length of stay }(p=0.05)\end{array}$ \\
\hline
\end{tabular}

Mean charges: Difference (95\% CI) 542 (-5121 to 6205) Rate of first hospitalization: Difference $(95 \%$ CI) 6 to 12 weeks: $-1 \%(-8 \%$ to $12 \%)$ Costs of nurse specialist total: $7,374(108 \pm 10)$

al days $(p=0.77)$ Acute care visits after discharge costs $(p=0.72)$ Rehospitalization or death $(p=$ Activity of daily living: $p<0.05$ Length of stay $(p<0.05)$ $(p<0.05)$ Readmission rates and ED were Outpatient primary care services: (30 days) $p<0.001$ 90 -day readmission $(p=0.003)$ uality of life $(p=0.0001)$ 30 -day rehospitalization $(p<$ Readmission rates reduced Three months Costs: not significant Follow-up Length of stay $(p=0.05)$ 


\begin{tabular}{|c|c|c|c|c|c|}
\hline $\begin{array}{l}\text { Yu et al., } \\
2015\end{array}$ & $N=178$ & $\mathrm{RCT}$ & $\begin{array}{l}\text { Readmission } \\
\text { Length of Stay } \\
\text { Self-care } \\
\text { Physical well-being }\end{array}$ & $\begin{array}{l}\text { RN-led } \\
\text { Nine months } \\
\text { Intensive follow-up }\end{array}$ & $\begin{array}{l}\text { Lower six-week readmission rate } \\
(p=0.048) \\
\text { Shorter length of stay }(p<0.001) \\
\text { Improved self-care }(p<0.05) \\
\text { Improved physical well-being at } \\
\text { three months }(p=0.05)\end{array}$ \\
\hline
\end{tabular}

Note $:$ APRN = Advanced Practice Registered Nurse; CI = Confidence Interval; ED = Emergency Department; MLHFQ =

Minnesota Living with Heart Failure Questionnaire; RN = Registered Nurse; OASIS = Outcome and Assessment Information Set 
Table 2.

Type and Frequency of Post-Discharge Contact with Patients

\begin{tabular}{|c|c|c|c|c|}
\hline Article & $\begin{array}{l}\text { Length of } \\
\text { Intervention }\end{array}$ & $\begin{array}{l}\text { Weekly } \\
\text { (High } \\
\text { Intensity) } \\
\end{array}$ & $\begin{array}{l}\text { Once or more per month } \\
\text { (Moderate Intensity) }\end{array}$ & $\begin{array}{l}\text { Once per month or less } \\
\text { (Low Intensity) }\end{array}$ \\
\hline $\begin{array}{l}\text { Coleman et al. } \\
2006\end{array}$ & 30 days & & Phone calls by APRN & \\
\hline $\begin{array}{l}\text { Harrison et al. } \\
2002\end{array}$ & 2 weeks & & & $\begin{array}{l}\text { Home visits were } \\
\text { conducted by the home } \\
\text { care nursing staff }\end{array}$ \\
\hline $\begin{array}{l}\text { Linden \& } \\
\text { Butterworth } 2014\end{array}$ & 90 days & & & $\begin{array}{l}\text { No home visits } \\
\text { Motivational } \\
\text { interviewing-based health } \\
\text { coaching and symptom } \\
\text { monitoring using } \\
\text { interactive voice response. }\end{array}$ \\
\hline Naylor et al. 1994 & 2 weeks & & Phone calls by APRN & \\
\hline Naylor et al. 1999 & 4 weeks & & Home visits by APRN & \\
\hline Naylor et al. 2004 & 3 months & $\begin{array}{l}\text { Home visits by } \\
\text { APRN for } 1 \\
\text { month }\end{array}$ & Home visits by APRN & \\
\hline Neff et al. 2003 & 30 days & & Home visits by nursing staff & \\
\hline $\begin{array}{l}\text { Ohuabunwa et al. } \\
2013\end{array}$ & 4 weeks & & $\begin{array}{l}\text { Phone calls and home visits by } \\
\text { the care transitions coach }\end{array}$ & \\
\hline Rich et al. 1995 & 90 days & & $\begin{array}{l}\text { Phone calls and home visits by } \\
\text { members of the study team }\end{array}$ & \\
\hline Russell et al. 2011 & $\begin{array}{l}\text { At least } 2 \\
\text { weeks }\end{array}$ & & $\begin{array}{l}\text { Phone calls and home visits by } \\
\text { members of the study team }\end{array}$ & \\
\hline Stauffer et al. 2011 & 3 months & & Home visits by APRN & \\
\hline $\begin{array}{l}\text { Williams et al. } \\
2010\end{array}$ & $\begin{array}{l}\text { Did not } \\
\text { specify }\end{array}$ & & Home visits by nursing staff & \\
\hline Yu et al. 2015 & 9 months & $\begin{array}{l}\text { Home visits by } \\
\text { RN for } 2 \\
\text { weeks }\end{array}$ & Phone calls by $\mathrm{RN}$ for 3 months & $\begin{array}{l}\text { Phone calls by RN every } 2 \\
\text { months for } 6 \text { months }\end{array}$ \\
\hline
\end{tabular}

Note: APRN $=$ Advanced Practice Registered Nurse; RN = Registered Nurse 